\title{
A COMPUTER PROGRAM TO EVALUATE THE WEBSITE OF BUSINESS ADMINISTRATION COLLEGES
}

\author{
Ahmad Abdelqader Abuseeni \\ Department of MIS, Taibah University, Medina, Saudi Arabi
}

\begin{abstract}
As a result of accelerating technological developments, it became very important to build a website that achieves the potential to keep pace with this development, at the same time, it is important to maintain the availability of the basic elements that achieve the goals, spatially the communicative goals, therefore, there is a growing need to build a website that achieves goals, especially in case of faculties of business administration, which need to be in line with developments to achieve communication goals with the environment and business partners.

The evaluation of the website can be carried out by ensuring the availability of the basic elements that achieve the desired objectives. Hence, this research is intended to provide a computer program that evaluates the website in a fast and effective manner, based on the results of previous studies in this field, the results of the program can easily provide a clear perception about the availability of the basic requirements for achieving the goals.

We hope presented computer program can be used to evaluate business administration college website, and this will contribute to supporting the trend towards the establishment of an electronic system for evaluating websites in general, as well as a step towards the computerization of all different evaluation procedures.
\end{abstract}

Keywords: Fundamental Objective Criteria, website total weight (TW), Technical and Graphical Criteria.

Cite this Article: Ahmad Abdelqader Abuseeni, A Computer Program to Evaluate the Website of Business Administration Colleges. International Journal of Information Technology \& Management Information System, 9(1), 2018, pp. 21-29.

http://iaeme.com/Home/issue/IJITMIS?Volume=9\&Issue $=1$ 


\section{INTRODUCTION}

When talking about the environment of educational institutions, the website is considered as the main link between these institutions and the surrounding environment. Therefore, it is essential that the website contains all the basic elements that help in achieving the objectives of communication between that institution and its partners in the work environment.

This research was arranged in six sections, The beginning was with the introduction which include the study problem and previous studies, in addition to research objectives and significance, research methodology was illustrated in detail in the second section, in the third section the program and its user interface are presented, the results and conclusion followed by future work were explained in sections four and five, finally references was introduced in section sex.

\subsection{The problem of the study:}

The problem of the study is that the process of evaluating any websites requires careful work to make sure that the basic elements are achieved and arranged in terms of priorities and a standard value for each basic or secondary element, and then extract the results, all these procedures depends on the manual work and is linked to the possibility of the existence of errors because of difference perspectives.

\subsection{Reviews of previous studies}

There are many researches that suggested tools for evaluating websites were the first of these researches Katz, W. (1997), Proposed a comprehensive standard for web site evaluation, after that, Vaigh, H. (2002), present what considered as the first Arab study to evaluate electronic content.

A study by Abuseeni.A.A.(2017) present a new tool to evaluate the website based on the availability of elements that support the communication objectives of the College of Business Administration, that tool has been adopted in this research and was converted into a computer program.

Massad, M. (2007), Compare the application of communicative goals in public and private universities in Egypt and the United Arab Emirates.

On the other hand, Ginsberg, S. (2007), results were confirmed by Hanan, J. (2015), both of them demonstrated the importance of the website of the faculty in the process of communication between teacher and students.

A study by Li, L, Finley, J., Pitts, J \& Guo, R. (2010), focus on the importance of communication between faculty members and students using e-mail. In the same context, Kuh, G. (1995), conclude that there is a positive effect of the use of the college website to improve the educational process. Moreover, Kuh, G. \& Hu, S. (2001) argued that a positive relationship existed between teachers and students outside of the formal classroom environment.

The use of chat or IM to facilitate student-interaction and virtual office hours in online courses and traditional courses has also been explored in recent studies by Myers, et al., (2004) and Jeong, (2007).

A study presented by Huett, (2004) concloude the richness of media choice bears mention. While effective in many ways, albeit less rich, the CMC media outlet entails less feedback potential which, in some cases, may impede message transfer.

Furthermore, Mahmoud, B. (1995) Explain the importance of continuous updates on the website of the College. 


\subsection{Research objectives}

The study aims to provide a computer program that can be used to evaluate the website of business administration colleges based on a tool that has been adopted in previous studies.

\subsection{Research significance}

The importance of the study stems from the provision of a computer program that presents results can facilitate the evaluation process of evaluating business administration website.

\section{RESEARCH METHODOLOGY}

The first step is to input the information about the availability of contents in the first main section which is Website Fundamental Objective Criteria with total of 72 weighting point, that implemented by five sub steps:

1. Input basic Information \& Responsibility by choosing one of three options for each element in that section: Available and Adequate or Available but not Adequate or Not Available.

2. Input the information about the availability of contents in the second section which is Accuracy by choosing one of three options for each element in that section.

3. Input the information about the availability of contents in the third section which is Contents, by choosing one of three options for each element in that section.

4. Input the information about the availability of contents in the fourth section which is Update, by choosing one of three options for each element in that section.

5. Input the information about the availability of contents in the fifth section which is Ease of Use, by choosing one of three options for each element in that section.

Second step is to input the information about the availability of contents in the second main section which is Website Technical and Graphical Criteria with total of 28 weighting point, that implemented by three sub steps:

1. Input the information about the availability of contents in the sixth section which is Compatibility, by choosing one of three options for each element in that section.

2. Input the information about the availability of contents in the seventh section which is Technical Support, by choosing one of three options for each element in that section.

3. Input the information about the availability of contents in the eighth section which is Attractiveness, by choosing one of three options for each element in that section.

Third the program will then read the input information and calculate the total weight(TW), if the website (TW) equal 100, that indicates it meets all the criteria of the standard, that is, it is available on the site and enough, if the website (TW) is less than 100 and greater than 54, then the site achieves the minimum standard items, so we can say that the standard items are available but insufficiently, else the site did not achieves the minimum standard items.

The overall algorithm is illustrated in Figure 1. 


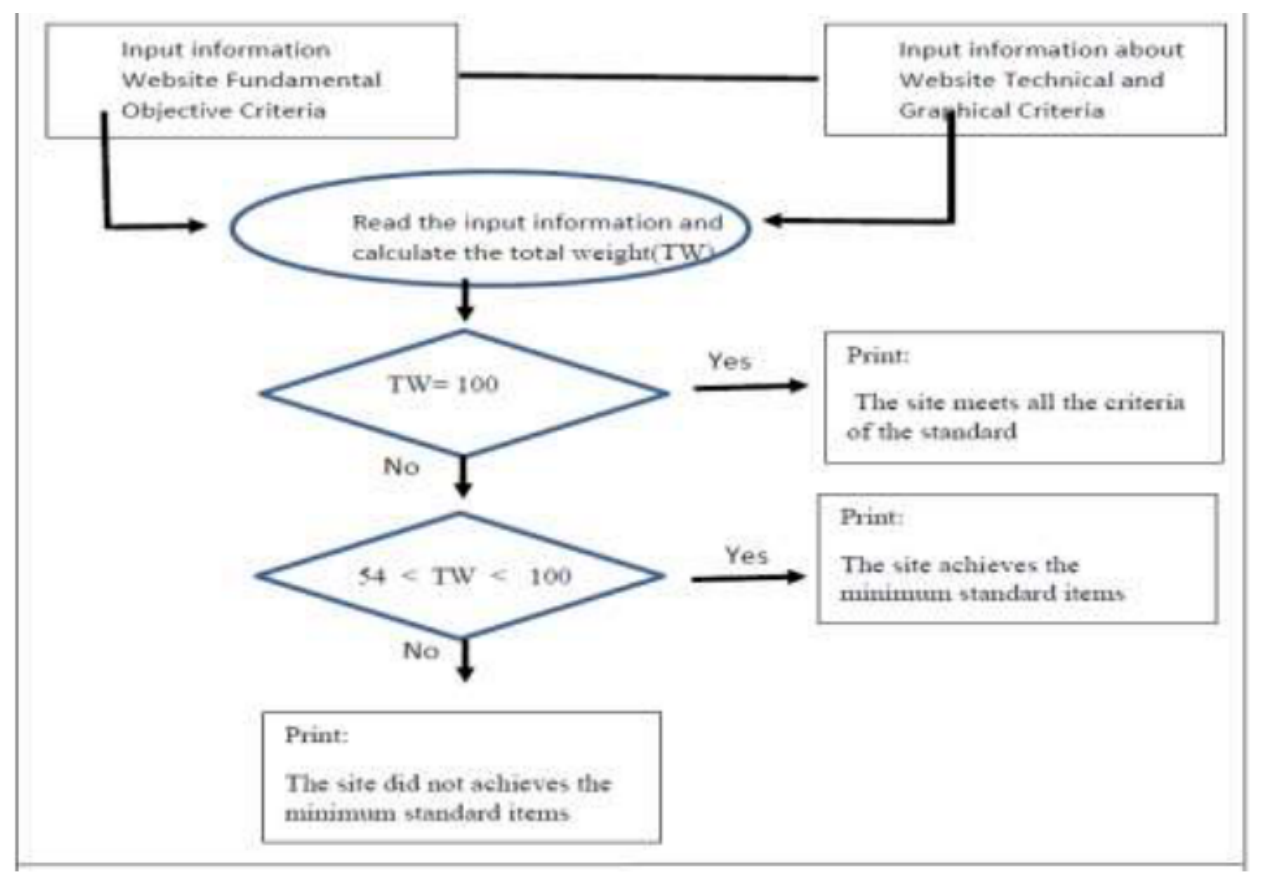

Figure 1 The overall algorithm

\section{THE PROGRAM}

The application was built using $\mathrm{CH}$, the pseudo code is illustrated in figure 2, the user interface was designed to be easy to use and attractive, so that the user can insert the input information and then see the total results, the user interface is illustrated in Figures, 3, 4, 5, 6, $7,8,9,10,11$.

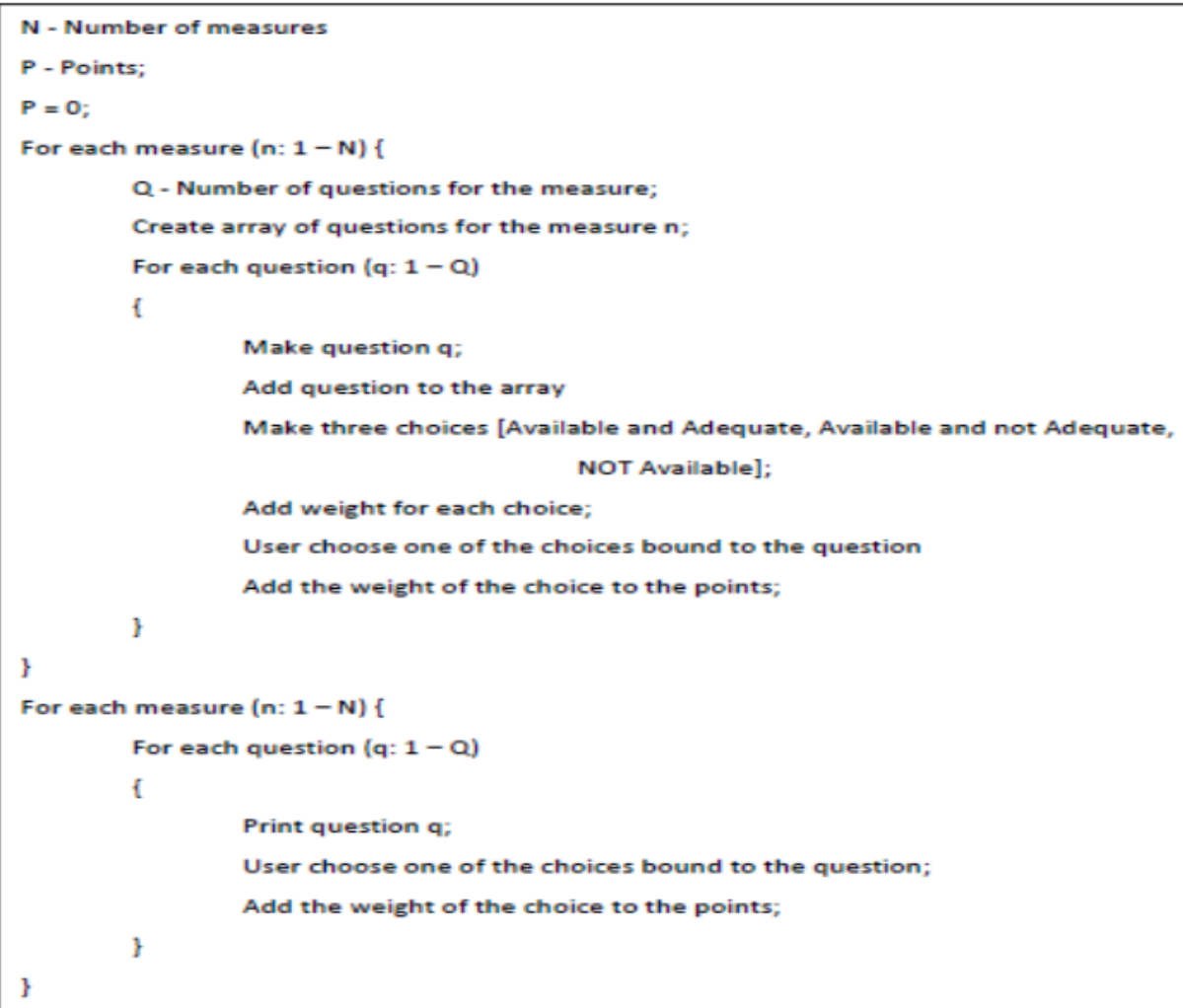

Figure 2 Pseudo code 
A Computer Program to Evaluate the Website of Business Administration Colleges

The first main section is website fundamental objective criteria start with a subsection titled basic information and responsibility as shown in Figures 3.

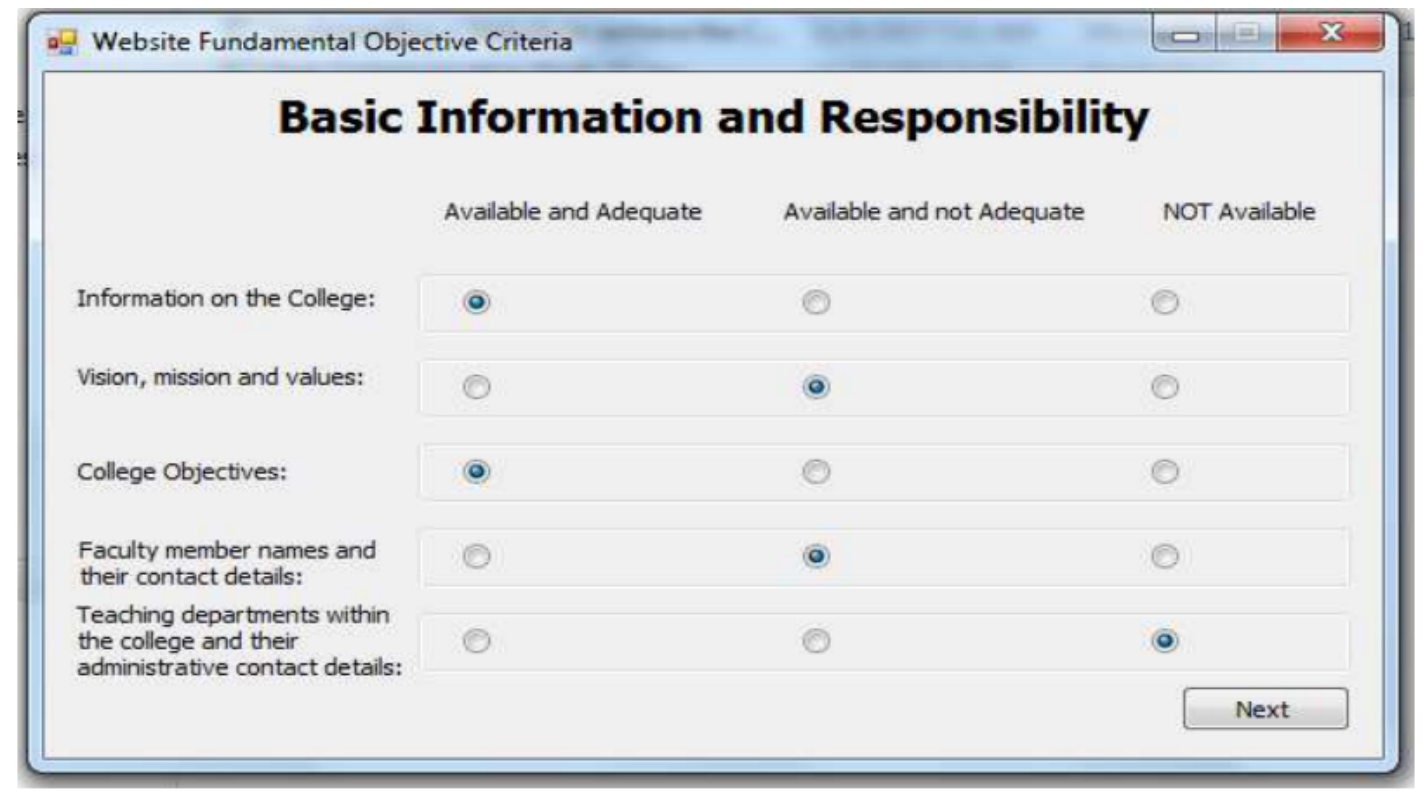

Figure 3 Basic information \& responsibility

The second subsection titled accuracy will be opened in a new window after ending the first subsection by clicking on next, as shown in Figures 4.

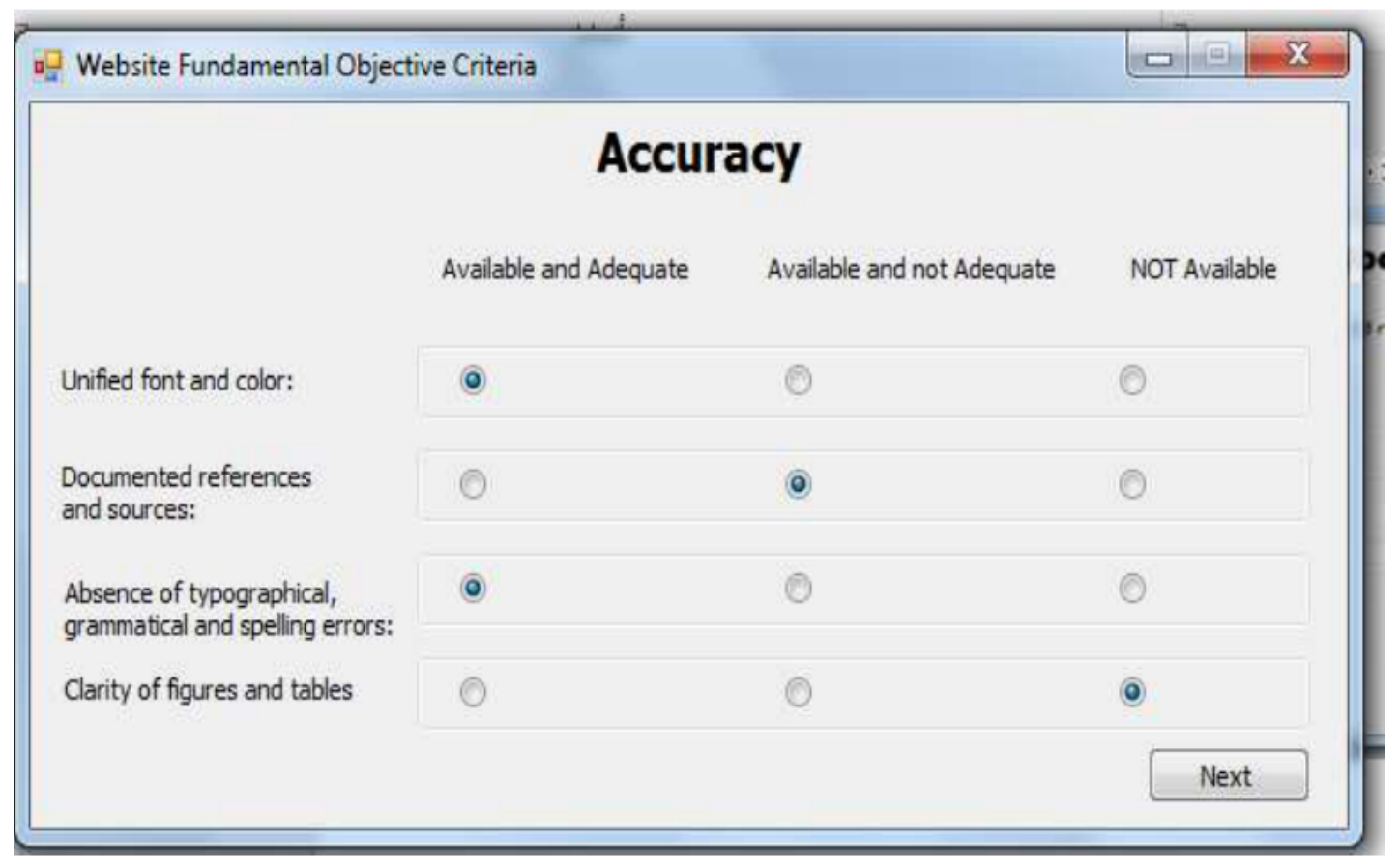

Figure 4 User interface to enter information about accuracy

The third subsection titled contents will be opened in a new window after ending the second subsection by clicking on next, as shown in Figures 5. 


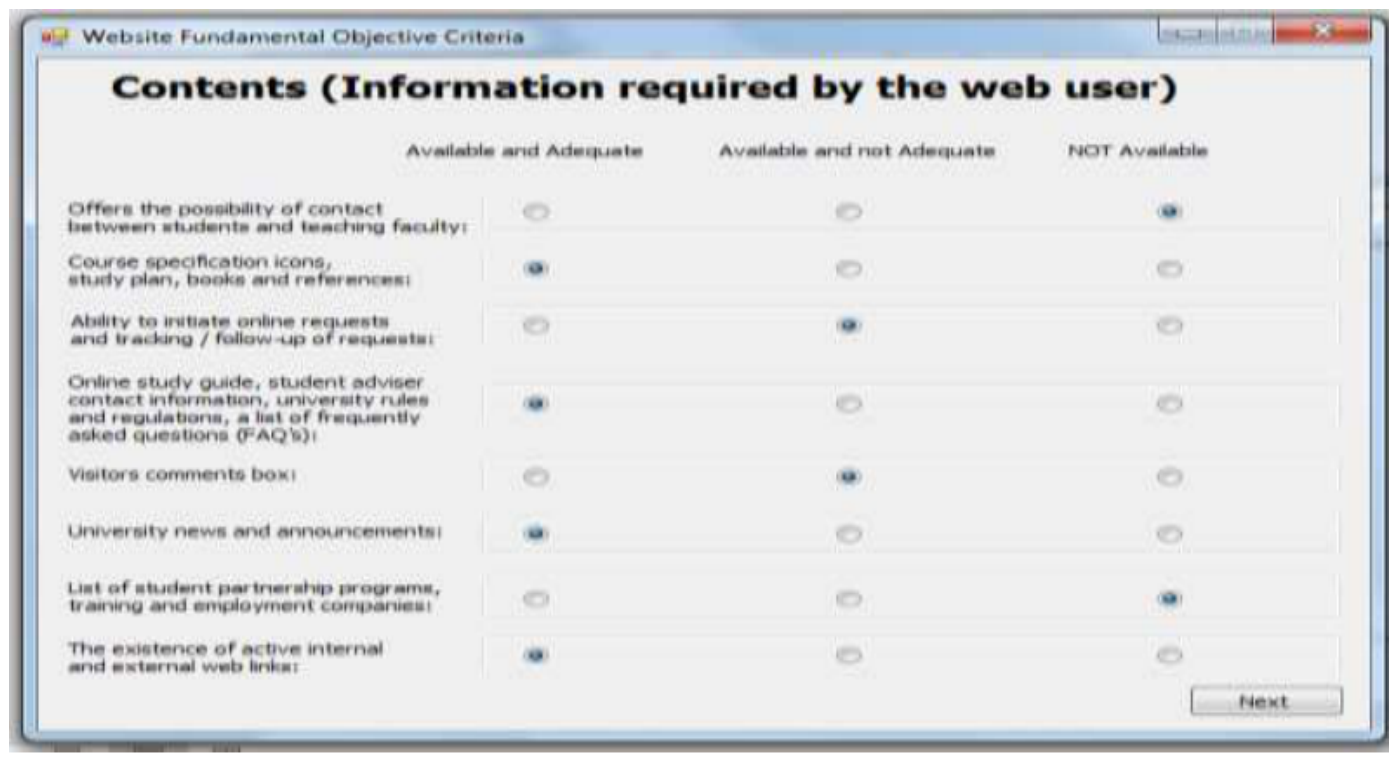

Figure 5 User interface to enter information about contents

The fourth subsection titled update will be opened in a new window after ending the third subsection by clicking on next, as shown in Figures 6 .

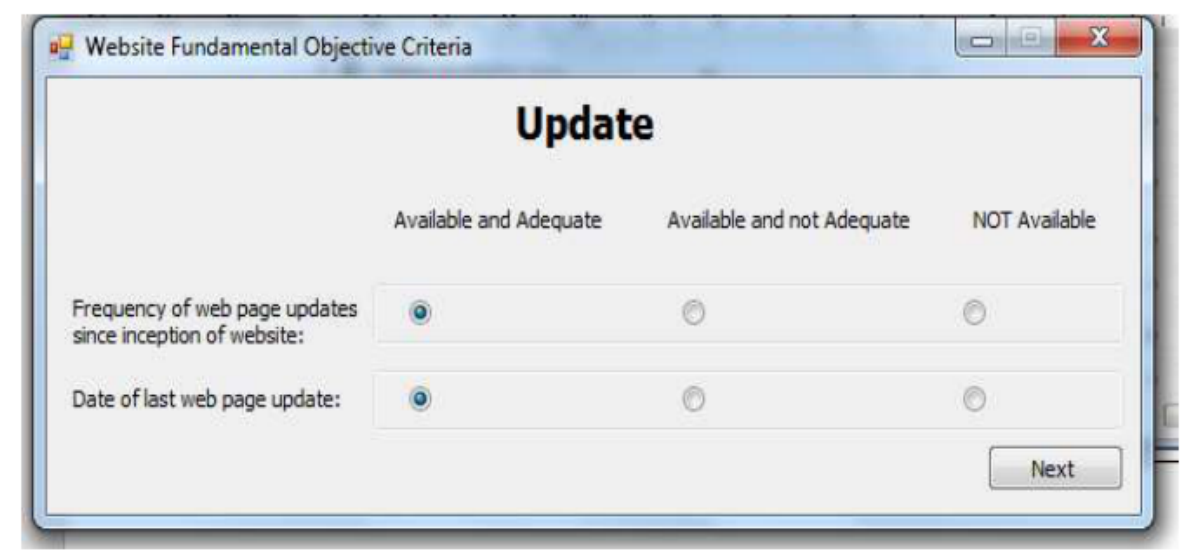

Figure 5 User interface to enter information about website update

The fifth subsection titled ease of use will be opened in a new window after ending the fourth subsection by clicking on next, as shown in Figures 7.

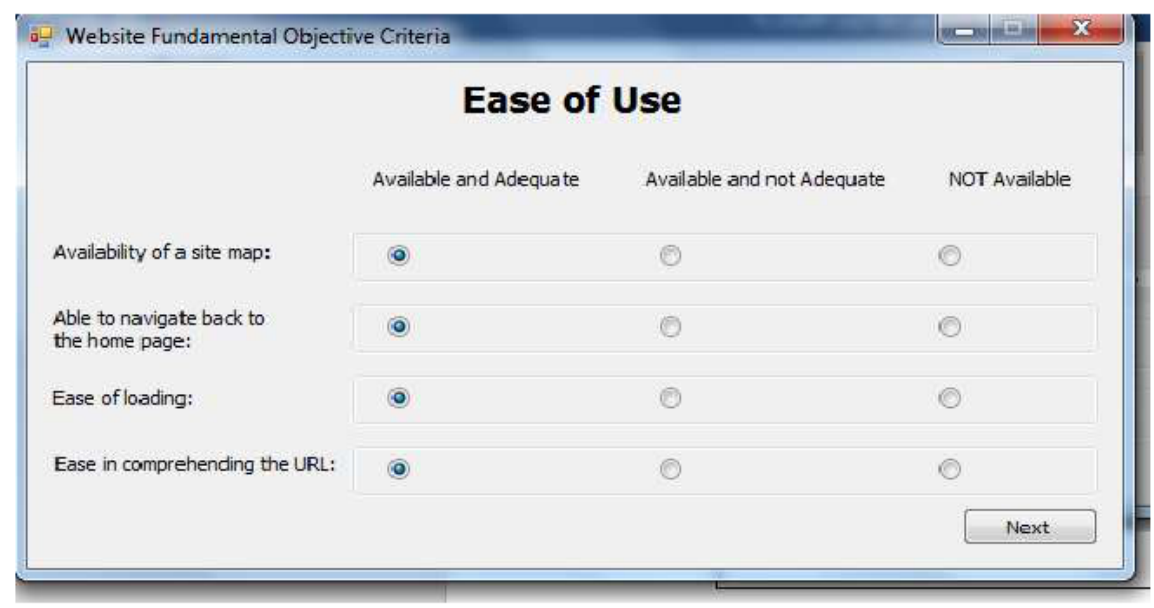

Figure 6 User interface to enter information about website ease of use 
The second main section which is Website Technical and Graphical Criteria will here be started with the first subsection titled compatibility, it will be opened in a new window after ending the previous subsection by clicking on next, as shown in Figures 8.

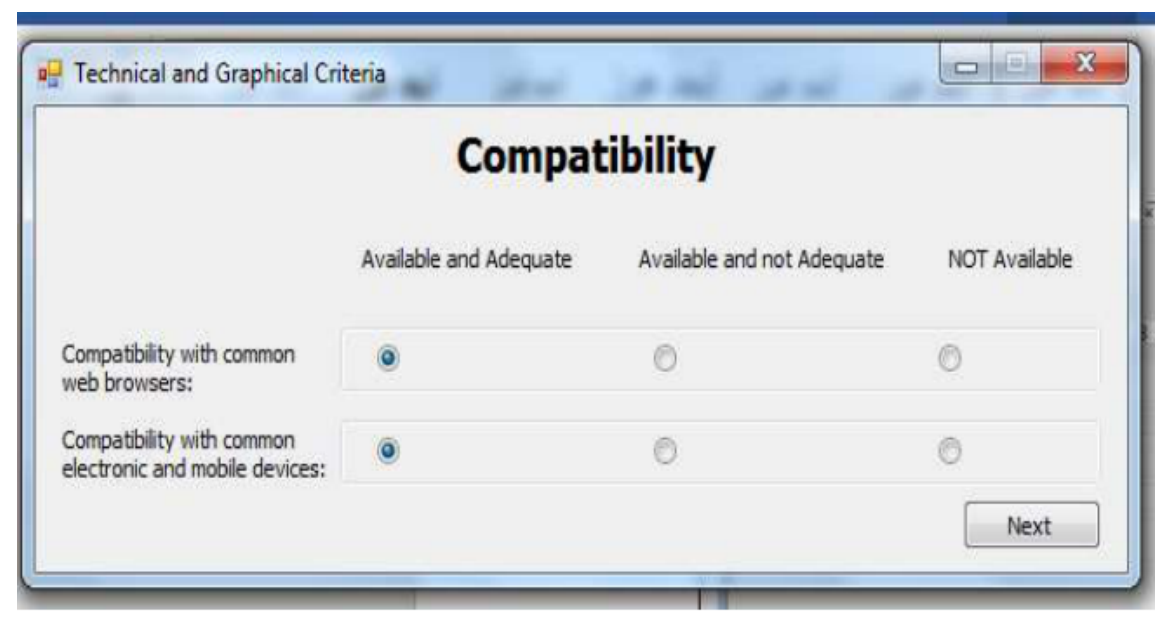

Figure 7 User interface to enter information about website compatibility

The second subsection titled technical and support will be opened in a new window after ending by clicking on next, as shown in Figures 9.

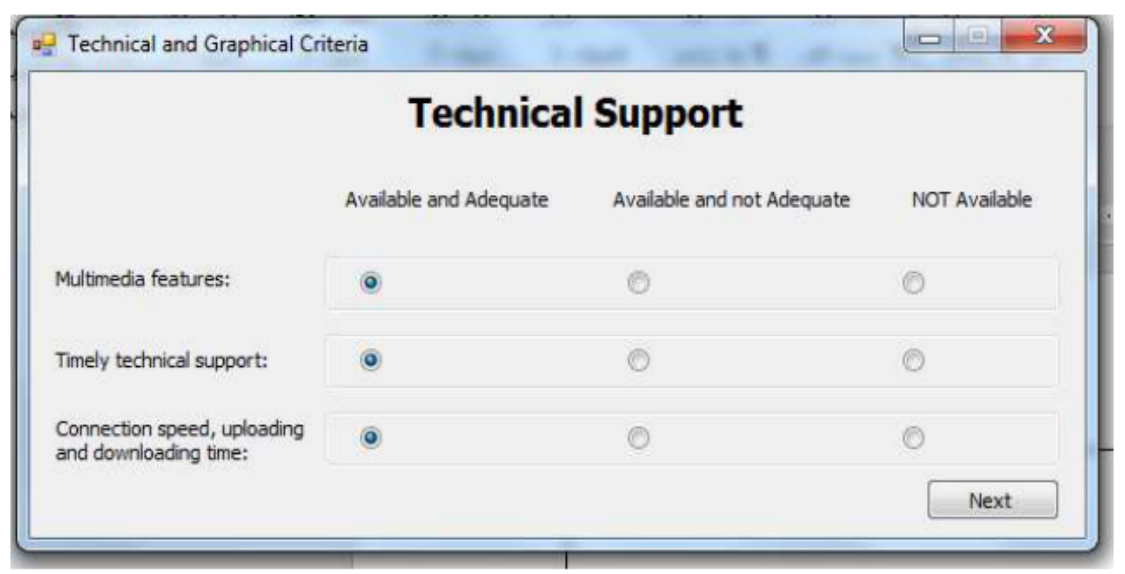

Figure 9 User interface to enter information about website technical support

The final subsection titled attractiveness will be started in a new window by clicking on next, as shown in Figures 10.

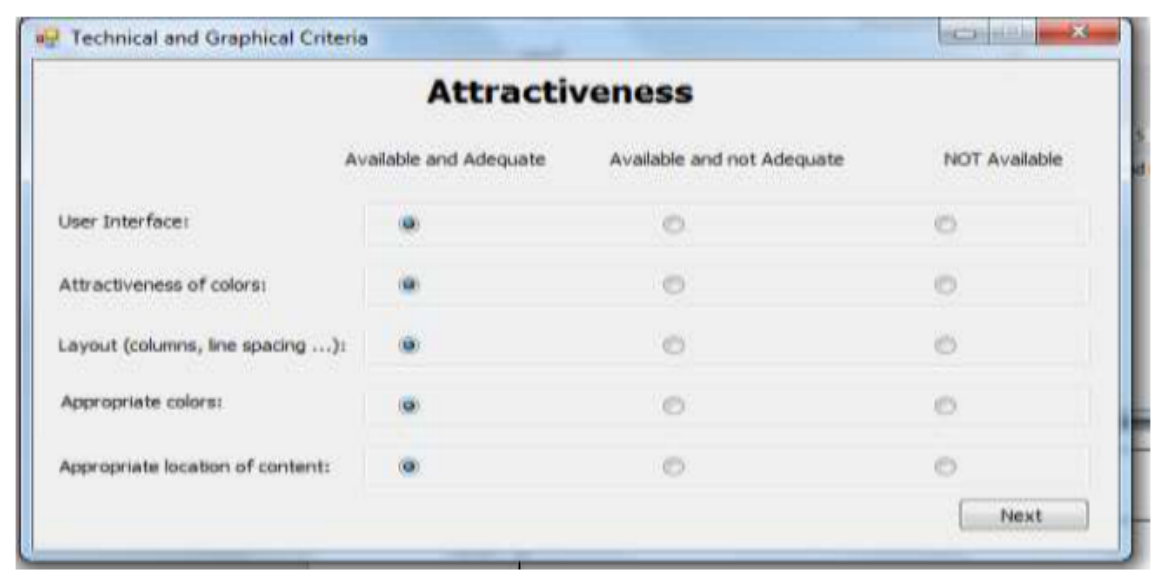

Figure 10 User interface to enter information about website attractiveness 
Finally, the program will illustrate the total of each main section and the whole total in a new window by clicking on the final next, as shown in Figures 11.

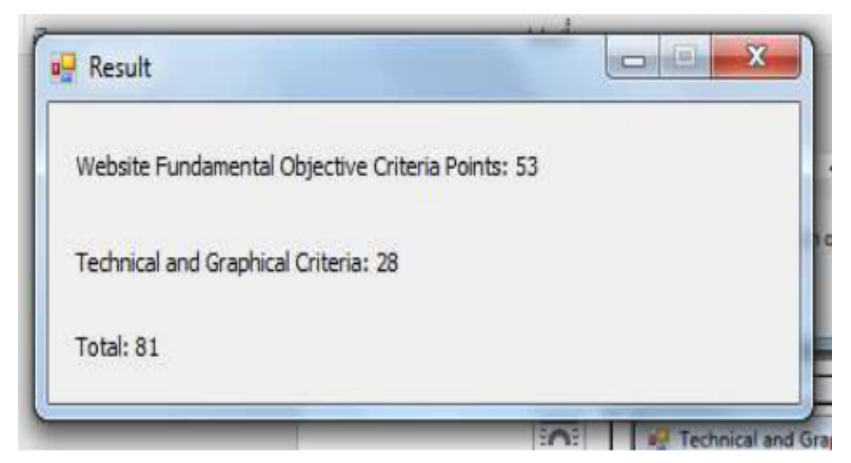

Figure 11 The total weight (TW )

\section{CONCLUSION}

In this research, a computer program was presented to provides the possibility of evaluating the website of faculties of business administration and universities, in a computerized manner based on a tool adopted in previous studies. Through this program, the process of evaluating the website became easier and more accurate, in addition what gives this program an extra advantage is that it gives the results in two phases, the first relates to website fundamental objective criteria and the second relates to website technical and graphical criteria, this gives the opportunity to learn more about the strengths and weaknesses of the website.

It is hoped that this program will facilitate the procedures for verifying the application of quality standards, especially regarding to the faculties of business administration and universities websites.

\section{FUTURE WORK}

Depending on the results of this research, it is expected that this program can pave the way as future work research to establish an integrated system for computerization procedures, to ensure the achievement of quality standards in educational institutions.

\section{REFERENCES}

[1] Abuseeni.A.A, Abu Sara M. R. (2017). A Software Program to Facilitate the Construction of Exam Scheduling in an Effective Manner, International Journal of Engineering Science and Technology (IJEST), Vol. 9 No.08 Aug 2017, pages 846-852.

[2] Ginsberg, S. (2007). Shared Characteristics of College Faculty Who Are Effective Communicators, The Journal of Effective Teaching, Vol. 7, No. 2, 2007, 3-20.

[3] Hanan, J. (2015). The Role of the Web in Achieving Communication Objectives of the Organization, the Forum for the third Friday the Saudi Public Relations and the Media, April 8 to 9.

[4] Katz, W. (1997). Introduction to Reference Work: Reference Services and Reference Processes. New York: McGraw Hill.

[5] Kuh, G. (1995). Student Learning Outside the Classroom: Transcending Artificial Boundaries, Jossey-Bass, Inc., San Francisco, California.

[6] Kuh, G. \& Hu, S. (2001). The Effects of Student-Faculty Interaction in the 1990s. The Review of Higher Education, Vol. 24, No. 3, pp. 309-332. 
[7] Jeong, W. (2007), Instant Messaging in On-Site and Online Classes in Higher Education. EDUCAUSE Quarterly, Vol. 30, No. 1, pp. 30 - 36, Re trieved May 22, 2009 from http://www.educause.edu/EDUCAUSE+Quarterly/EDUCAUSE QuarterlyMagazineVolu $\mathrm{m} /$ InstantMessaginginOnSiteandOn1/157440.

[8] Li, L, Finley, J., Pitts, J \& Guo, R. (2010). Which is a better choice for student-faculty interaction: Synchronous or asynchronous communication? Journal of Technology Research.

[9] Huett, J. (2004), Email as an Educational Feedback Tool: Relative Advantages and Implementation Guidelines. International Journal of Instructional Technology and Distance Learning, Vol. 1, No. 6, pp. 35-44.

[10] Massad, M. (2007). The Role of the Internet and the Press in Providing Adolescents with Information. Unpublished Master Thesis, Institute of Family Studies, Childhood, Ain Shams University, Department of Information.

[11] Myers, S., Bishop, D., Sayee, S., and Kelly, J. (2004), Virtual Office Hours: Tutoring Students in Statistics and Economics. Proceedings of the OCDE Convergence of Libraries, Retrieved January 2009 from http://oln.org/conferences/OCDE2004/papers/Virtual_Office_Hours.pdf.

[12] Vaigh, H. (2002). Evaluating Sources of Reference to Electronic Information Available on the Internet and CD-ROM Files, Recent Trends in Libraries and Information, 